УДК 902/904

DOI: https://doi.org/10.33782/eminak2020.1(29).395

\title{
СИСТЕМНЫЙ ПОДХОД В КЛАССИФИКАЦИИ КЕРАМИКИ БУДЖАКСКОЙ КУЛЬТУРЫ
}

\author{
Светлана Иванова \\ Институт археологии Национальной академии наук Украины (Киев, Украина) \\ e-mail svi1956@gmail.com \\ ORCID: https://orcid.org/0000-0002-3318-8244
}

У статті охарактеризовано методику класифікації кераміки буджацької культури Північно-Західного Причорномор'я. Системній підхід дозволяє об'єктивно підійти до розробки класифікаційних схем різних типів посуду. У роботі застосовується наступна ієрархічна схема систематизації кераміки: відділ - категорія - тип - варіант.

Представлені графічні класифікаційні схеми.

Ключові слова: кераміка, буджацька культура, Північно-Західне Причорномор'я

Буджакская культура Северо-Западного Причерноморья является составной частью ямной культурно-исторической общности (КИО). Основной категорией памятников являются подкурганные захоронения. Керамика выступает преобладающей категорией погребального инвентаря, составляя более $40 \%$ от общего числа находок. Всего для анализа и построения классификации в работе были использованы данные о 467 сосудах буджакской культуры, происходящих из погребений и насыпей курганов Северо-Западного Причерноморья. Техника изготовления керамики традиционна вручную, с применением шамота, известняка или песка в качестве основного отощителя, с обработкой поверхности лощилом, шпателями, пучками растительности. Цвет поверхности варьирует от розовых и желтых оттенков до темно-серого. Поверхность некоторых категорий сосудов (банки) покрыта ангобом 1 .

Заметим, что в той или иной степени керамика рассматривалась и в обобщающих работах, посвященных различным аспектам истории буджакской и катакомбных культур². Однако классификации этих исследователей имеют ряд недостатков: они базировались на индивидуальном (субъективном) подходе, отличном у каждого автора. На наш взгляд, классификация керамики должна базироваться на таком подходе, который позволит подойти объективно и к ее описанию и, собственно, к классификации.

С одной стороны, следует согласиться с мнением Л.С. Клейна о том, что универсальных принципов классификации археологических артефактов пока не существует ${ }^{3}$.

\footnotetext{
${ }^{1}$ Иванова С.В. Ямная (буджакская) культура Северо-Западного Причерноморья // Древние культуры Северо-Западного Причерноморья. Одесса: СМИЛ, 2013. С. 211-254.

2 Яровой Е.В. Древнейшие скотоводческие племена юго-запада СССР (классификация погребального обряда). Кишинев: Штиинца. 1985. 122 с.; Дергачев В.А. Молдавия и соседние территории в эпоху бронзы. Кишинев: Штиинца, 1986. 222 с.; Тощев Г.Н. Средний период бронзового века ЮгоЗапада СССР. Запорожье. 1987. 227 с. Деп. В ИНИОН АН СССР 19.06.1987, № 29903; Алексеева И.Л. Курганы эпохи палеометалла в Северо-Западном Причерноморье. Киев: Наукова думка. 1992. 131 с.; Субботин Л.В. Северо-Западное Причерноморье в эпоху ранней и средней бронзы // Stratum plus. 2000. № 2. С. 350-387.

3 Клейн Л.С. Понятие типа в современной археологии // Типы в культуре. Ленинград: ЛгУ. 1979. С. 55; Клейн Л.С. Археологическая типология. Ленинград: АН СССР, 1991. 448 с.
} 
Достаточно часто археологическую классификацию понимают как иерархию классов, хотя это лишь один из ее вариантов, для которого существует специальный термин «таксономическая классификация». Типология термина «археологическая классификация» достаточно разнообразна, охватывая различные аспекты этого понятий. $\mathrm{C}$ другой стороны, имеются теоретические работы, обосновывающие основные принципы типологии и классификации, в том числе керамики, в которых краеугольным является понятие типа как системы, для которой характерно устойчивое сочетание признаков. Таким образом, в основе классификации керамики должна быть не личная точка зрения автора, а системный подход. Отмечают, что выделение того или иного типа сосудов должно быть основано, прежде всего, на создании его структурной схемы, т.е. на выделении его дискретных признаков, связанных между собой5.
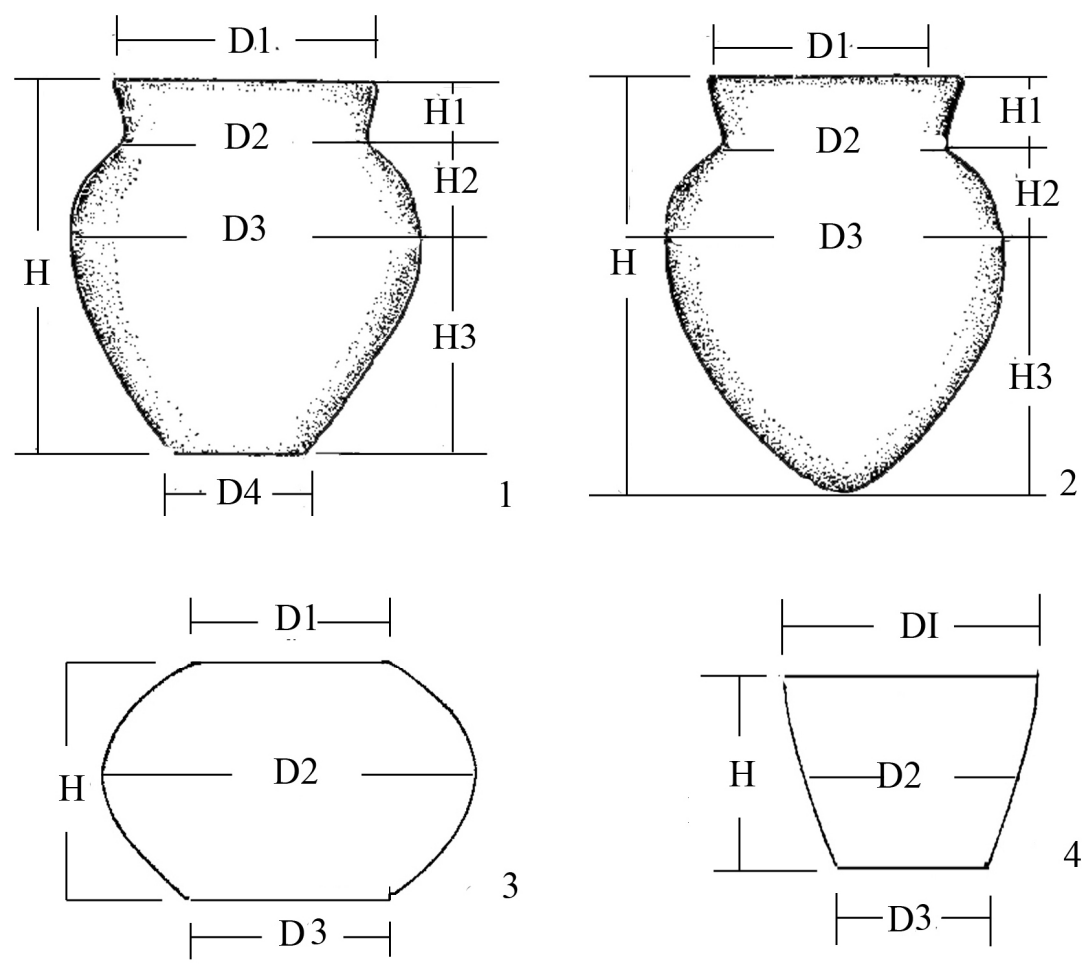

3
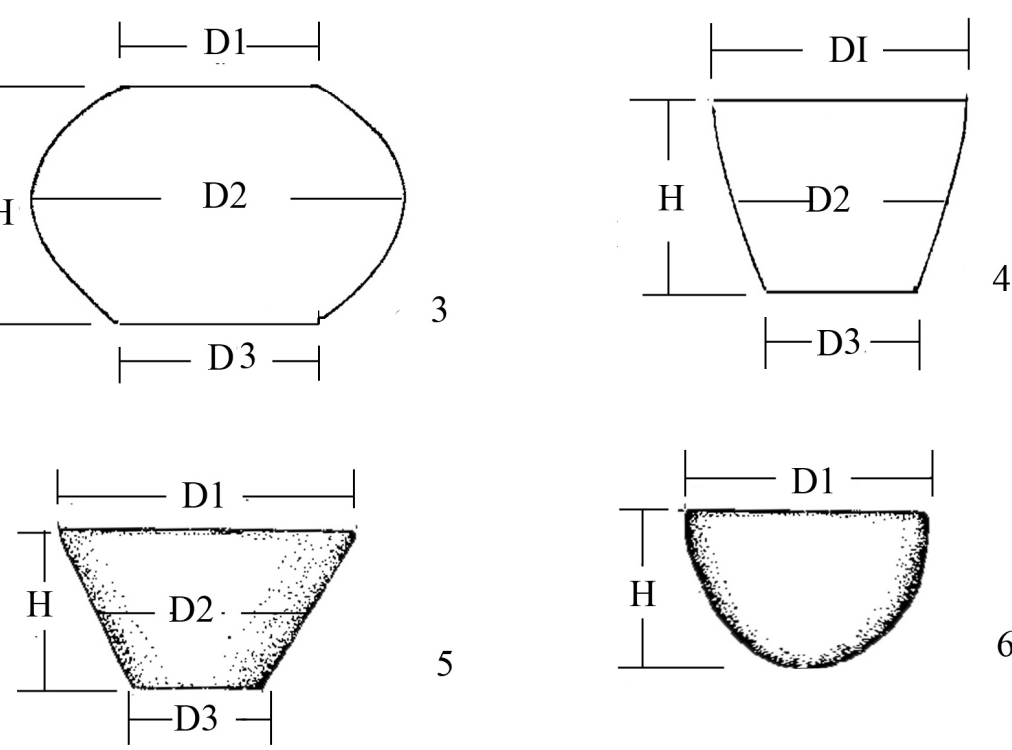

6

Рис. 1 Схема основных замеров керамики буджакской культуры:

1,2 - сосуды с шеей; 3-6 - бесшейные сосуды.

\footnotetext{
4 Бочкарев В.С. Классификация в археологии. Терминологический словарь-справочник. Москва: Наука. 1991. С. 9-23.

5 Шер Я.А. Типологический метод в археологии и статистика // VII Международный конгресс доисториков и протоисториков. Доклады и сообщения археологов СССР. Москва. 1966. С. 253-266.
} 
Поэтому наш подход основывался не только на традиционном в археологии формально-типологическом методе, но и на использовании элементов системного анализа. Каждый тип керамики имеет определенную структуру, проявляющуюся в системе признаков - составных элементах сосуда. В зависимости от цели исследования может меняться количество и характер включаемых в классификацию признаков, выбор их связан с пониманием целостности исследуемого объекта (сосуда) как функциональной единицы, которая состоит из взаимосвязанных компонентов 6 .

Для настоящего исследования достаточным является выделение таких основных элементов сосуда как тулово, дно, венчик; их различные формы и размеры, будучи объединены в систему, являются структурной схемой того или иного типа сосуда. Отметим мнение специалистов о том, что при ручном и домашнем изготовлении керамики посуда демонстрирует большое разнообразие признаков, почти каждый сосуд индивидуален, морфологические характеристики часто неустойчивы ${ }^{7}$. Исходя из этого выделение более подробной градации нерационально, хотя возможно. Тулово сосуда рассматривается как доминирующая его часть, поскольку основной функцией и назначением сосуда является быть ёмкостью, дно и венчик имеют второстепенное значение. Дополнительным элементом являются ручки, т.к. они присутствуют не на всех сосудах, выступая в то же время типообразующим признаком.

Форма сосуда и его структура взаимосвязаны. Рассмотрение структуры, т.е. сочетания различных морфологических признаков, характеризующих сосуд, лежит в основе системного подхода в построении различного рода классификаций керамики энеолита и бронзового века разных территорий - как западных8, так и восточных 9 . Это касается и морфологии сосудов, и их стилистики. В Северо-Западном Причерноморье системный подход к анализу керамики был использован В.Г.Петренко при классификации посуды и орнаментации усатовской культуры ${ }^{10}$.

В работе применена следующая иерархическая схема систематизации керамики (от высшего к низшему): отдел - категория - тип - вариант.

В первую очередь, керамика делится на две большие группы по признаку оформления верхней части. В классификациях керамики эпохи бронзы за этими группами закрепился термин «отдел». Таким образом, в отдел 1 включены сосуды с шеей, в отдел 2 - бесшейные сосуды.

\footnotetext{
6 Боковенко Н.А. Этюд о скифских бронзових котлах Северного Причерноморья // Клейн Л.С. Археологическая типология. Ленинград: АН СССР, 1991. С. 256-263.

7 Мочалов О.Д. Керамика погребальных памятников эпохи бронзы лесостепи Волго-Уральского междуречья. Самара: СГПУ, 2008. С. 27.

8 Czebreszuk, J. Spoleczniści Kujaw w początkah epoki brązu .Poznań: UAM. 1996. S. 11-15; Szmyt M. Between West and East. People of the Globular Amphora Culture in Eastern Europe 2960-2350 BC. Poznań: Adam Mickiewicz University. 1999. Р. 18-25, fig. 4-6; Манзура И.В. Проблема формирования культур раннего бронзового века на Северо-Восточных Балканах // Stratum plus. 2001-2002. № 2. C. 468-481; HübnerE. Jungneolithische Gräber auf der Jütischen Halbinsel. Typologische und chronologische Studien zur Einzelgrabkultur. Kobenhavn: Der Kongelige Nordiske oldskirftselskab. 2005. S. 165-310; Wlodarczak P. Kultura keramiki sznurowej na wyžynie Małopolskiej. Krakow: Instytut archeologii i etnologii PAN, 2006. S. 13-20; Przybyl A. Spoleczności późnoneolitycznej kultuty pucharów lejkowatych na Kujawach. Problem wplywów z kręgu kultury badeńskiej. Poznań: UAM. 2009. P. 96-96, tab. 10-11.

9 Мочалов О.Д. Керамика погребальных памятников эпохи бронзы лесостепи Волго-Уральского междуречья. Самара: СГПУ,2008. С. 28, табл. 5; С. 47-48, табл. 14; С. 107, табл. 28.

10 Патокова Э.Ф., Петренко В.Г., Бурдо Н.Б., Полищук Л.Ю. Памятники трипольской культуры в Северо-Западном Причерноморье Киев: Наукова думка. 1989. С. 105-109, рис. 35-38.
} 


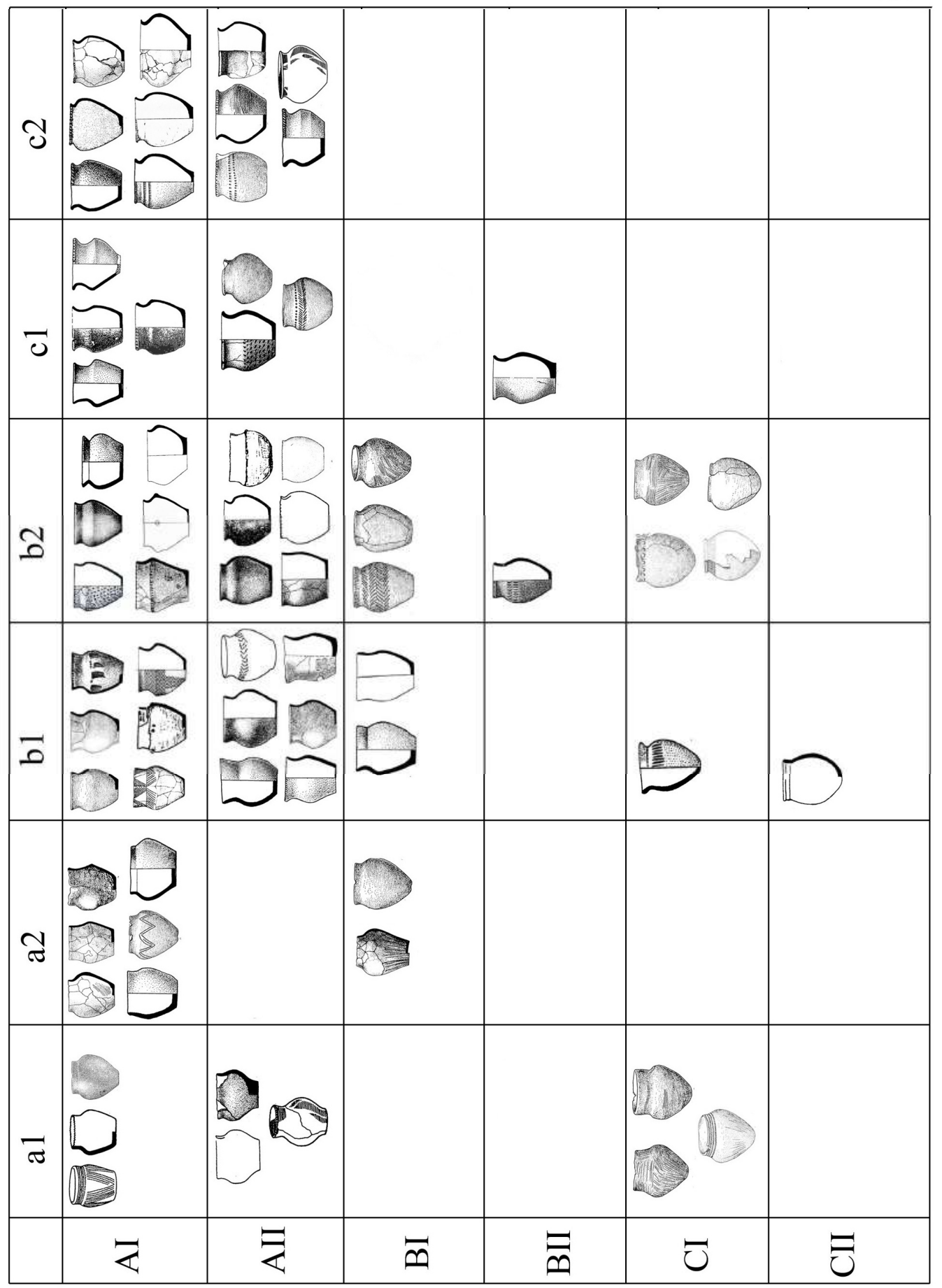

|⿱宀0) 
Следующим уровнем в построении классификации является выделение различных категорий посуды на основании морфологических признаков 11.

В отделе 1 (сосуды с шеей) выделены следующие категории: горшки и горшковидные сосуды, амфоры и амфоровидные сосуды, кубки, кувшины, аски.

В отделе 2 (бесшейные сосуды) выделены следующие категории: банки, чаши, миски, кружки.

Имеются редкие керамические формы, представленные единичными экземплярами: прямоугольный сосуд-курильница, сосуды «с носиком», глиняные воронки, импортные сосуды необычных типов: кубок с ручками под венчиком, т. н. «кратеры», биконические чаши. Эти сосуды не рассматривались по данной классификации.

Следующий уровень классификации представляет собой выделение типов в рамках каждой из категорий керамики на основе совокупности признаков, отражающих форму основных элементов сосуда - тулова, венчика, дна. Каждый элемент имеет несколько характеристик (группу признаков), их различное сочетание в тех или иных типах внутри одной категории является основой построения типологии.

Вариант определяется, исходя из стилистических признаков сосуда (орнаментация, если она присутствует).

Мы используем две типологические схемы для классификации керамики, которые характеризуют два выделенных отдела: в каждой из них использовались несколько отличные наборы морфологических признаков, связанных с профилировкой сосудов и их пропорциями (рис. 1). Для удобства систематизации разные признаки отмечены различными символами - прописными и строчными буквами латинского алфавита, римскими и арабскими цифрами. Комбинация различных морфологических признаков отражает структурную схему сосуда и служит основой выделения типа в рамках системного подхода.

В работе применена следующая иерархическая схема для выделения типа: отдел - группа признаков - признак.

\section{Отдел 1. Сосуды с шеей.}

Группа признаков 1 (критерием выделения является форма тулова и дна).

Признаки:

A - сосуды с плоским дном и сферическим туловом, когда наибольший диаметр тулова примерно равен высоте тулова или больше его (H2 : D3 = 0,9-1,1);

$\mathrm{B}$ - сосуды с плоским дном и овально-удлиненным туловом, при этом высота тулова больше диаметра венчика (H : D3 = 1,2-1,3);

C - сосуды с округлым дном. Незначительное количество такой посуды позволило нам объединить их в один тип, независимо от пропорций тулова.

Группа признаков 2 (критерием выделения являются пропорции тулова).

Признаки:

I - наибольшее расширение тулова приходится на его верхнюю треть - т.е. плечи ( $\mathrm{H} 3>\mathrm{H} 2)$;

II - наибольшее расширение тулова приходится на среднюю часть сосуда (H3 = Н2).

Группа признаков 3 (критерием выделения является форма венчика).

Признаки:

\footnotetext{
11 При ее анализе в данной работе мы использовали разработки Е.В. Ярового и В.А. Дергачева для керамики ямной культуры Северо-Западного Причерноморья, уточняя и систематизируя их.
} 
$\mathrm{a}$ - прямой цилиндрический венчик (D1 = D2);

b - отогнутый наружу венчик D1 > D2);

c - венчик S-видной формы (с загнутым наружу краем).

Группа признаков 4 (критерием выделения является высота венчика):

Признаки:

1 - высокий венчик (Н1 : H = 0,3-0,4);

2 - короткий венчик (H1: $\mathrm{H}=0,1-0,2)$.

Отдел 2. Бесшейные сосуды.

Группа признаков 1 (критерием выделения является форма тулова и дна).

Признаки:

A - сосуды с плоским дном и сферическим туловом (а также «грушевидным» и «чугунковидным»);

В - сосуды с плоским дном и коническим туловом;

C - сосуды с плоским дном и биконическим туловом;

$\mathrm{D}$ - сосуды с плоским дном и цилиндрическим туловом;

E - сосуды с округлым дном.

Группа признаков 2 (критерием выделения являются пропорции тулова).

Признаки:

I - наибольшее расширение сосуда приходится на его устье, это так называемые «открытые сосуды» (D1 > D2);

II - наибольшее расширение тулова приходится на его верхнюю треть - т.е. плечи (H3 > H2);

III - наибольшее расширение тулова приходится на среднюю часть сосуда (Н3 = $\mathrm{H} 2)$;

IV - тулово не имеет расширения, диаметр устья примерно равен диаметру тулова и диаметру дна или диаметр дна несколько меньше (D1 = D2 = D3).

Группа признаков 3 (критерием выделения является соотношение диаметра устья к высоте).

Признаки:

a - сосуды средних пропорций (H : D =0,9-1,0);

$\mathrm{b}$ - сосуды высоких пропорций $(\mathrm{H}: \mathrm{D}=1,1-1,3)$;

c - сосуды приземистых пропорций $(\mathrm{H}: \mathrm{D}=0,7-0,8)$.

Группа признаков 4 (критерием является наличие или отсутствие поддона

1 - имеется поддон (выделенное дно);

2 - без поддона (дно не выделено).

Орнаментация относится к стилистическим признакам керамики. Она присутствует лишь на части сосудов и различается по технике выполнения декора и по орнаментальным композициям. В целом, при оформлении керамики эпохи палеометалла, выделяются рельефная орнаментация (валики, порой, расчлененные), защипы, налепы, не имеющие функционального назначения (т.е. не ручки сосудов), и углубленная орнаментация (шнуровая, прочерченная, штампованная). В буджакской керамике преобладает шнуровой вид орнаментации, иногда сочетающийся с отпечатками полой трубочки. Среди основных мотивов присутствуют выполненные отпечатками шнура горизонтальные ряды линий в верхней части сосуда (по венчику или близ устья), зачастую в сочетании с углами, зигзагами, треугольниками, косыми линиями, заполненными внутри также шнуровыми отпечатками. Реже 
встречаются рельефный (пальцевые защипы, валики) или прочерченный орнамент, но достаточно распространены насечки, углубления или защипы по краю венчика. Некоторые виды орнамента связаны с теми или иными категориями посуды, к примеру, шнуровой более характерен для банок и амфоровидных сосудов, налепные валики - для амфор, а насечки по краю венчика - для горшков.

Основываясь на описанных общих принципах классификации, обратимся собственно к керамике буджакской культуры.

\section{Отдел 1: сосуды с шеей.}

Горики и гориковидные сосуды наиболее многочисленны - 161 экземпляр (или 34,5\% всего количества керамики), они варьируют по пропорциям и профилю (рис. 2). Преобладают плоскодонные сосуды, округлодонных известно около десятка, более половины из них сосредоточены на правом берегу Южного Буга, отражая связи с южнобугским вариантам ямной КИО и указывая на Побужье как на контактный регион двух культурных ареалов.

Можно отметить следующие типы горшков: 1) средних пропорций, с выделенными плечами и высоким венчиком, прямым, отогнутым наружу или S-видной формы (27,4\%) - Ala1, AIb1, AIc1; 2) средних пропорций, с выделенными плечами и невысоким венчиком, прямым, отогнутым наружу или S-видной формы $(35,4 \%)$ - AIa2, Alb2, AIc2; 3) средних пропорций с туловом округлых очертаний (максимальное расширение в средней части) и высоким венчиком, прямым, отогнутым наружу или Sвидной формы (17,8\%) - AIIa1, AIIb1, AIIc1 (2.19. 1-17; 24, 25); 4) средних пропорций с туловом округлых очертаний и невысоким венчиком, отогнутым наружу или Sвидной формы (9,7\%) - AIIb2, AIIc2 (2.19. 18-23; 27-31); 5) горшки высоких пропорций, чаще с выделенными плечами и невысоким, прямым или отогнутым наружу венчиком (9,7\%) - Bla2, BIb1, BIb2.

Короткий венчик различного профиля более характерен для сосудов с расширением в верхней трети тулова (с выделенными плечами), высокий венчик чаще встречается на горшках с расширением в средней части тулова. В целом, в этой категории посуды преобладают плоскодонные горшки с выделенными плечами и коротком венчиком, отогнутым наружу. Немногочисленны во всех типах горшки с прямым (цилиндрическим) венчиком, небольшую группу составляют горшки высоких пропорций, единичны - приземистых очертаний.

Округлодонные горшки имеют разную форму тулова и венчика, объединяет их округлая форма дна. Преобладают сосуды с выделенными плечиками, форма венчика разнообразна (CIa1, CIb1, CIb2): высокий прямой или отогнутый венчик, невысокий отогнутый наружу венчик.

В некоторых типах горшков выделяются варианты, где имеется орнамент (рис. 2). Но орнаментировано немногим более десятка сосудов; чаще всего это - насечки или отпечатки шнура на плечиках или под венчиком, иногда - елочные композиции или полуовалы. На шести экземплярах зафиксированы налепы в виде горошинок, поверхность единичных сосудов оформлена пальцевыми защипами, лощением или расчесами. Распространены насечки, защипы или отпечатки шнура по краю венчика, так оформлены около трети горшков.

Дно горшков крепилось снаружи к стенкам и заглаживалось, но почти на всех сосудах видны закраины. Помимо средних и крупных экземпляров, имеются небольшие, высотой до 10 см, но они единичны. 


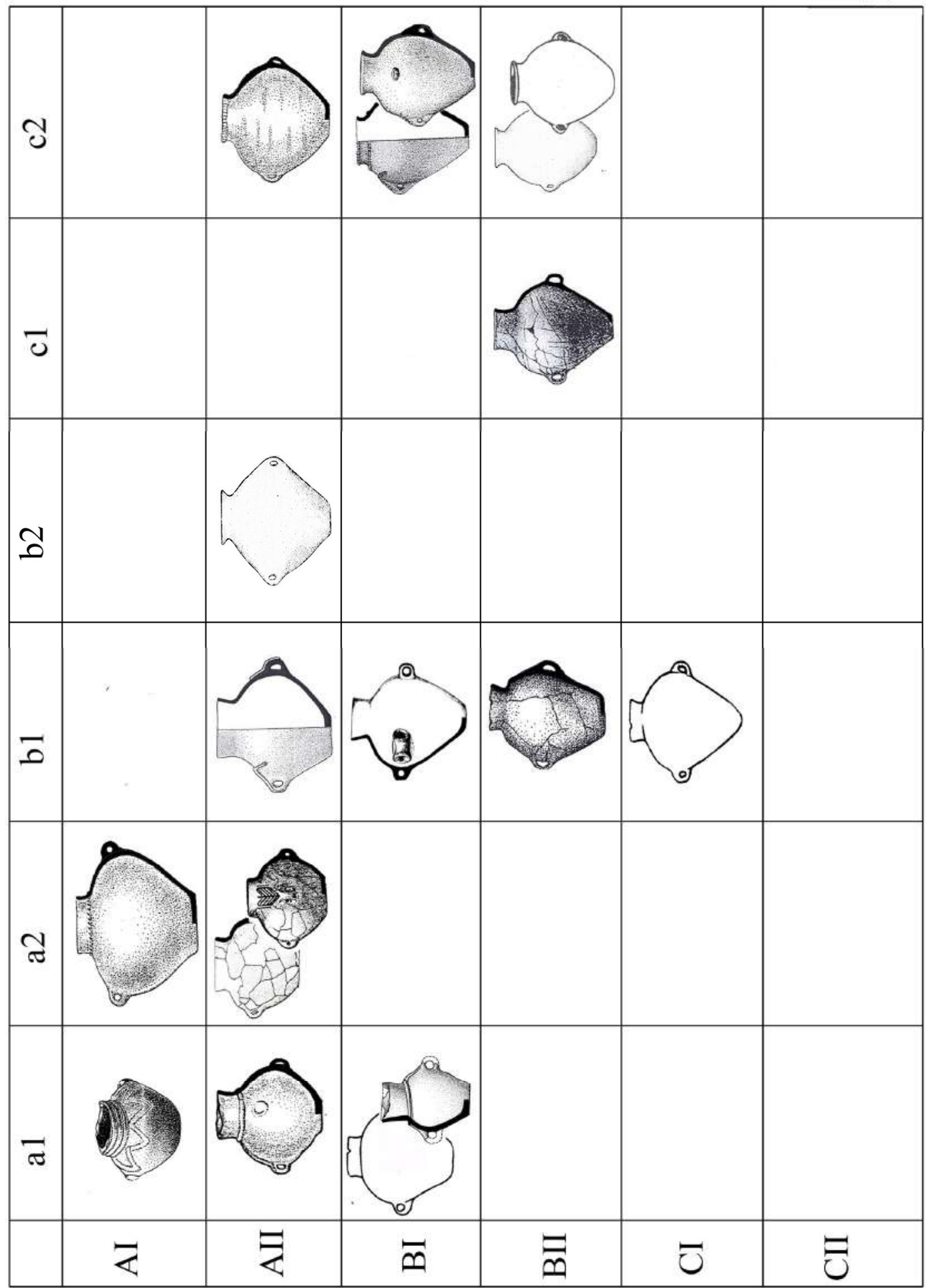

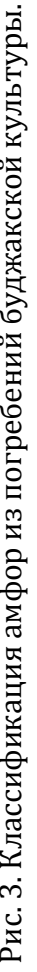




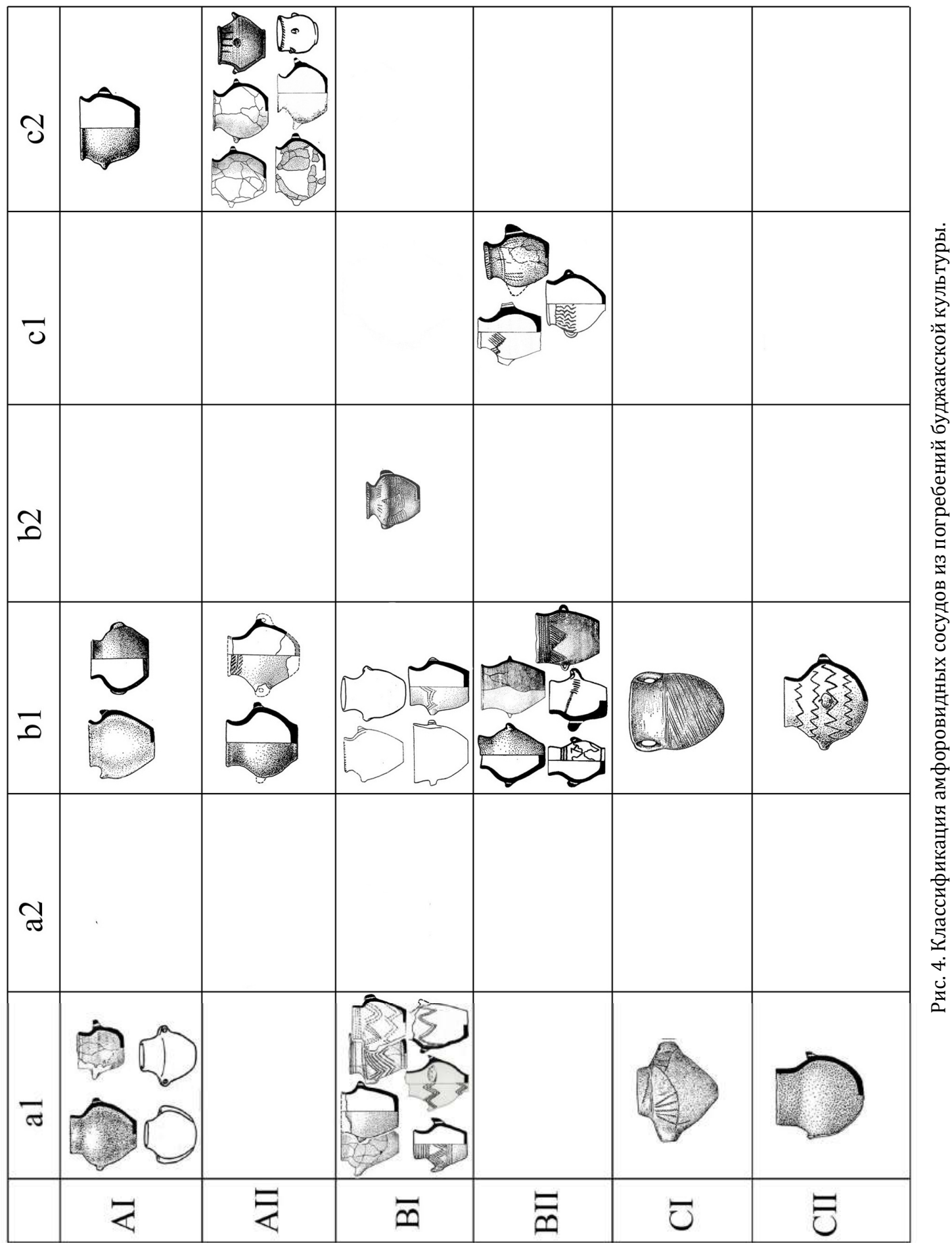


Амбборы и амфборовидные сосуды - 78 экземпляров (16,7\%). При соотнесении буджакской керамики с этой категорией мы исходим из общепринятого определения, что амфорой является сосуд крупных размеров с широким туловом, узким горлом и двумя ручками ${ }^{12}$. В энеолите и бронзовом веке, в отличие от античности, размер сосуда, ширина горла, наклон венчика и ширина тулова были разнообразны, стандарты, характерные для более поздних эпох, были не столь жесткими или вообще отсутствовали. Мы сочли возможным выделить три вида посуды в рамках этой категории: амфоры, амфоровидные сосуды, амфоры КША.

Амфоры (21 экз.) - высотой от 20 до 40-50 см (рис. 3). Ввиду небольшого количества они не составляют значительных серий ${ }^{13}$. Сводная таблица позволяет предварительно выделить три типа - со сферическим туловом - Ala1, AIa2, AIIa1, с овальным удлиненным туловом AIIc2, BIc2, BIIc1, BIIc2 и промежуточный тип - Bib1, BIIb1, Clb1. Обычно амфоры имеют цилиндрическое, реже отклоненное наружу горло и, преимущественно, плоское дно. Отметим некоторую биконичность тулова амфоры из Бурсучен $1 / 19$, выраженное расширение в верхней трети тулова амфоры из ГураГалбене 2/5. Амфора из погребения Ясски 5/26 уникальна и имеет яйцевидное неустойчивое дно. Аналогии ей тоже единичны - амфора из Белозерки Херсонской области. Выделяется амфора из Казаклии $3 / 1$, на тулове которой имеется роспись в виде полос, нерегулярно нанесенных коричневой краской ${ }^{14}$. Петлевидные ленточные ручки, иногда с канелюрами, чаще всего расположены в наиболее широкой части тулова амфор, иногда ниже. Наиболее распространенным элементом оформления амфор являются валики, переходящие с ручек на тулово (5 экземпляров) и имеющие вид «усов» или «рогов» (букрании?). Реже встречаются валики, опоясывающие горло (3 экземпляра), валики, соединяющие основание венчика с ручками (2 экземпляра). Из 21 экземпляра лишь 5 лишены какой-либо орнаментации, о двух отсутствуют сведения, один представлен фрагментом нижней части.

Часть амфор изготовлена из плотного, хорошо отмученного теста и имеет розовую подлощенную поверхность (Белолесье к.1, насыпь; Огородное, к. 1 насыпь; Градешка I, 5/11.

Отметим, что мы включили в каталог буджакских сосудов комплекс из амфоры и горшка, традиционно относимые к катакомбному погребению Траповка $1 / 18$. Исследование полевой документации и фотоархива позволили В.Г.Петренко установить, что эти сосуды находились в отдельной яме, которая была перерезана входным колодцем катакомбного захоронения ${ }^{15}$. Поэтому их следует относить к находкам из насыпи кургана и связывать, на наш взгляд, с буджакской культурой. Амфора имеет высокое цилиндрическое горло, опоясанное налепным валиком, концы которого спускаются по плечикам к ручкам, для удобства мы оставили за ней прежние координаты - Траповка 1/18.

Амфоровидные сосуды (57 экз.) - относительно небольшого размера экземпляры (высотой до 20 см), достаточно разнообразных конфигураций (рис. 4). Они не исчерпываются теми несколькими округлыми или овальными очертаниями корпуса, которыми традиционно представляют этот тип посуды в обобщающих работах.

\footnotetext{
12 Матюшин Г.Н. Археологический словарь. Москва: Просвещение, 1995. С. 9.

13 Иванова С.В. Ямная (буджакская) культура Северо-Западного Причерноморья...

14 Дергачев В.А. Указ. раб. С. 46.

15 Петренко В.Г., Островерхов А.С., Сапожников И.В. Новый курган эпохи энеолита-бронзы в Нижнем Поднестровье // Старожитності Степового Причорномор'я та Криму. 2002. № X. С. 61.
} 
Формы тулова в пределах даже этих традиционных форм очень разнообразны, некоторые из них повторяют типы горшков или кубков, отличаясь лишь прикрепленными к ним ручками. Тем не менее, согласно приведенному выше определению признаков, характерных для амфор, они должны быть отнесены к данной категории керамики. Условно мы включили в нее сосуд из погребения Вишневое 17/4. В нем изначально отсутствует венчик, но конфигурация тулова не позволяет отнести его к банкам или другим бесшейным сосудам.

В большинстве своем амфоровидные сосуды имеют плоское дно, хотя известны экземпляры с округлым или яйцевидным дном. Ручки (две, реже четыре, в единичном случае пять) расположены в средней части тулова или на плечиках, чаще всего это конические, пирамидальные или уплощенные парные налепы, в каждом из которых имеется одно или два вертикально проколотых отверстия. Реже встречаются псевдотунельные и петлевидные ручки, единичны ручки-«ушки» с горизонтальными проколами; на одном сосуде известны «арочные» ручки.

Значительные серии сосудов не выделяются ввиду большого разнообразия форм тулова. Тем не менее, можно отметить такие типы: 1) со сферическим или приземистым туловом, высоким цилиндрическим или небольшим отогнутым венчиком: AIa1, Alb1, AIIb1, AIIc2; 2) с овально-вытянутым туловом и высоким горлом, прямым или слегка отогнутым наружу: BIa1, BIb1, BIIb1, BIIc1. Характерно, что выделяются типы, где орнаментация тулова является традиционной и типы, где она отсутствует.

Имеются амфоровидные сосуды, украшенные шнуровым орнаментом по горлу и плечикам или по всему тулову (рис. 4). Орнамент в определенной степени соотносится с известным на баночных сосудах - зигзаги, треугольники, но композиции в большинстве своем выглядят более простыми. Некоторые сосуды имеют лощеную поверхность красновато-коричневого цвета (Курчи I, 1/6; Градешка I, 5/1; Оланешты 14/1), что выделяет их из всей буджакской посуды, для которой такая обработка поверхности не характерна. Единична находка амфоровидного сосуда с большими петлевидными ручками, соединяющими край венчика и тулово - Ковалевка VIII, $1 / 24$.

Амфоры культуры шаровидных амфбор (9 экз.) - это сосуды с выпуклым туловом и своеобразной орнаментацией, имеющей аналоги в керамическом комплексе культуры шаровидных амфор (рис. 5), есть и неорнаментированные экземпляры. Известны амфоры с 2 или 4 ручками, петлевидными или в виде налепов, расположенными, как правило, на плечиках. Они объединяются в два типа, согласно классификации М. Шмит ${ }^{16}$.

Кубки и кубковидные сосуды - 38 экземпляров (8,1\%) - достаточно разнообразны по форме и размерам (рис. 6). Традиционно к этому типу относят сосуды с округлым или вытянутым туловом и высоким, отогнутым наружу (или прямым) венчиком, в одном случае край венчика загнут вовнутрь. Чаще всего кубки имеют стройные высокие пропорции, зафиксированы также округлые, острореберные или приземистые формы тулова, но при этом венчик в кубках всегда составляет не менее трети всей высоты сосуда. По форме тулова можно условно выделить два типа: 1) с максимальным расширением в верхней трети тулова - AIb1 и с расширением в средней части тулова AIIa1, AIIb1. Большинство изделий имеют средние размеры, до

16 Szmyt M. Between West and East. People of the Globular Amphora Culture in Eastern Europe 29602350 BC. Poznań: Adam Mickiewicz University, 1999. P. 126-127, fig. 37, 38. 
20 см высотой, есть экземпляры большей и меньшей высоты. Известны кубки, орнаментированные оттисками шнура: в виде параллельных отпечатков по венчику и заштрихованных треугольников, опущенных вершинами вниз по плечикам, зигзага, «елочки», древовидных отпечатков. Иногда на венчиках имеются насечки. Одним экземпляром представлен сосуд, украшенный по всему сосуду прочерченным орнаментом в виде параллельных горизонтальных линий - Каменка, к. 1, насыпь.

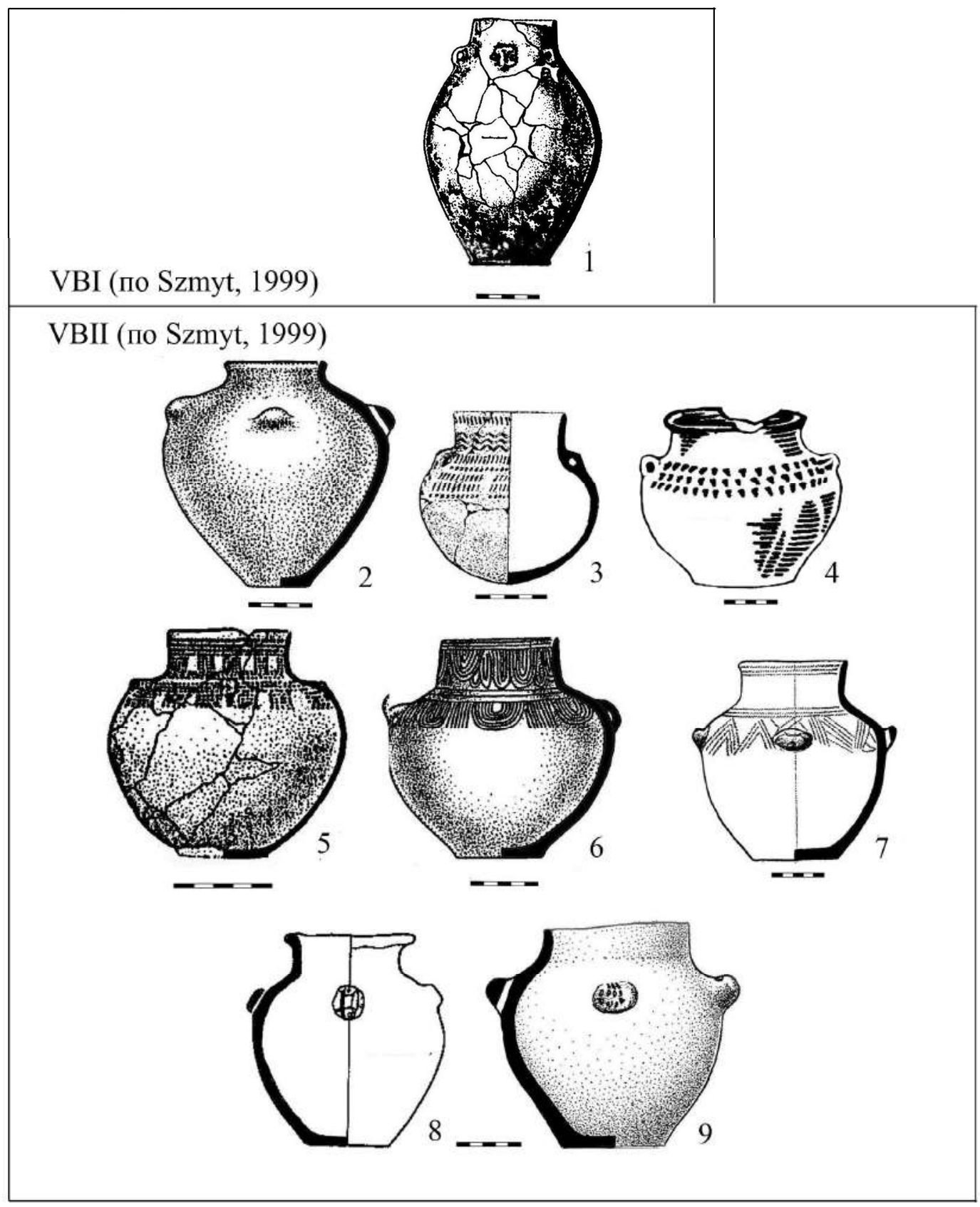

Рис. 5. Амфоры из погребений буджакской культуры, имеющие параллели в культуре шаровидных амфор:

1 - Маркулешты 3/4; 2 - Корпач 2/13; 3 - Мокра 3/4; 4 - Ефимовка 2/14; 5 - Каменка (Окница) 3/14; 6 - Корпач 2/7; 7 - Градешка I, 5/11; 8 - Татарбунары 1/2; 9 - Новоселица 19/14. 


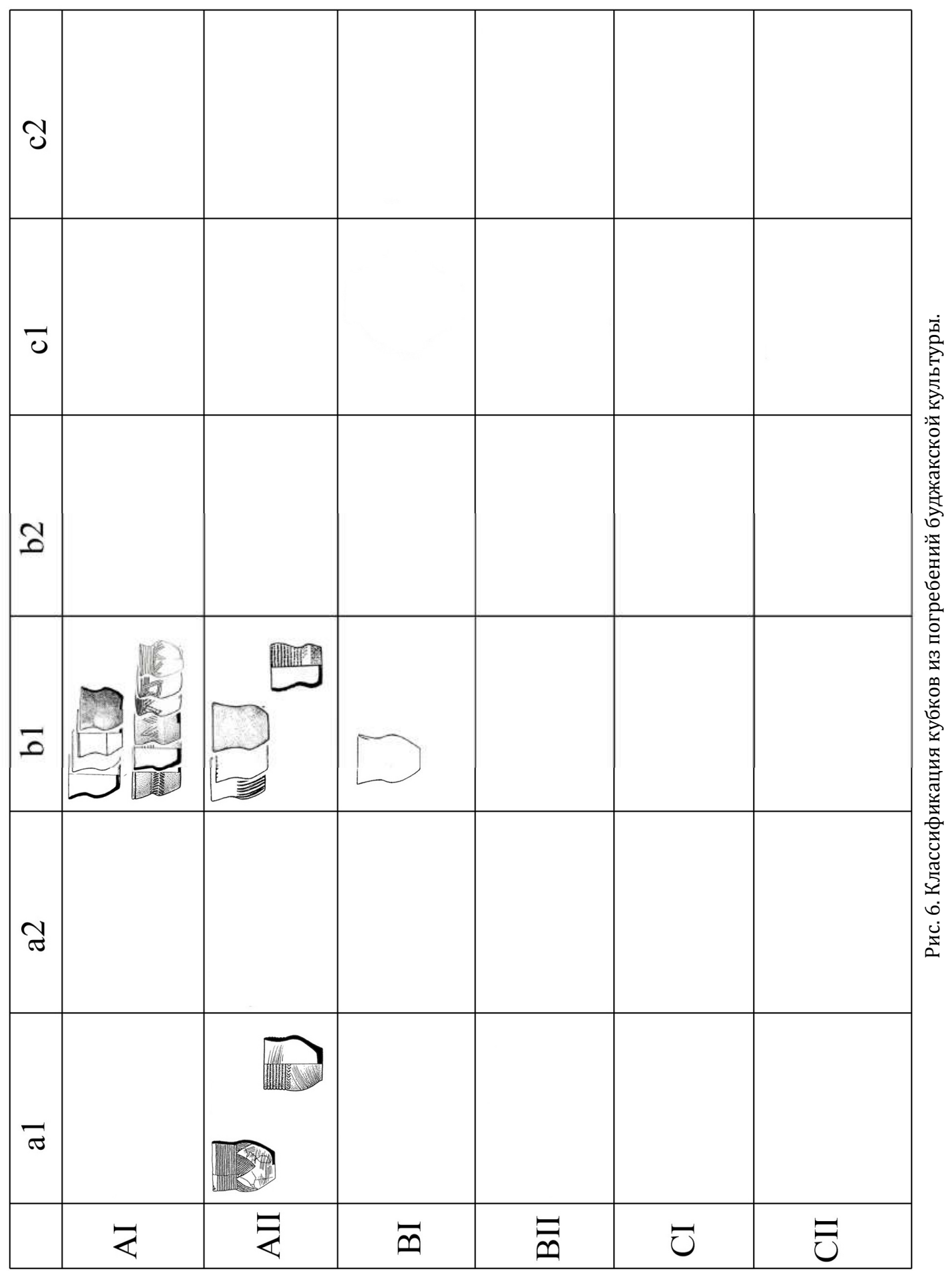



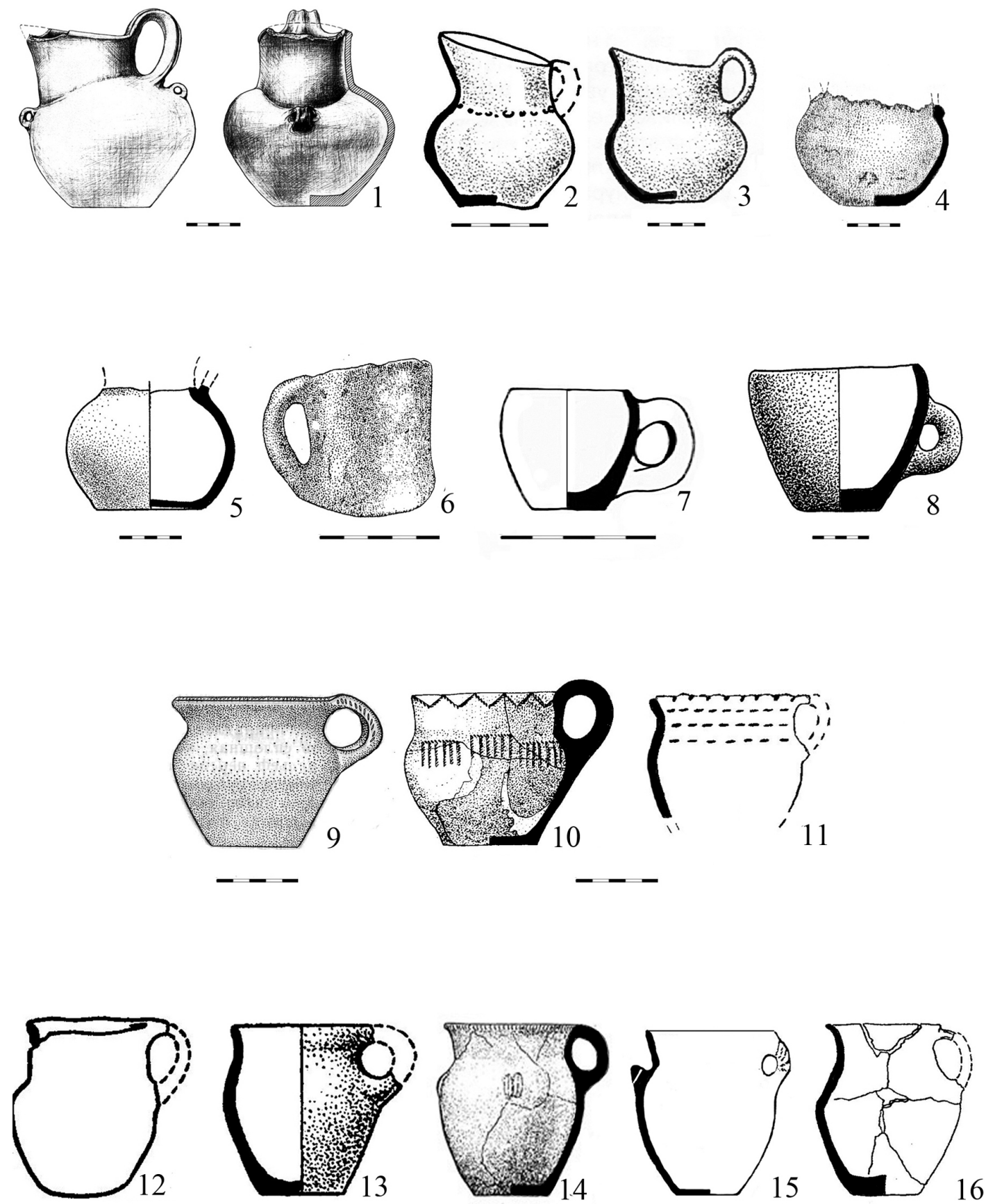

Рис. 7. Аскосы, кружки и кувшины из погребений буджакской культуры:

1 - Матроска, к.1, разрушенное погребение; 2 - Кубей 21/5; 3 - Глубокое 2/11; 4 - Урсоая 3/6;

5 - Дивизия II, 5/7; 6 - Ковалевка I, 3/2; 7 - Новоградковка 2/9; 8 - Вишневое 54/1; 9 - Маяки III, 1/18; 10 - Оланешты 1/28; 11 - Фрикацей 1/5; 12 - Болград 1/12; 13 - Новоградковка 2/9; 14 - Тараклия 16/5; 15 - Струмок 1/3; 16 - Новая Долина 3/5. 


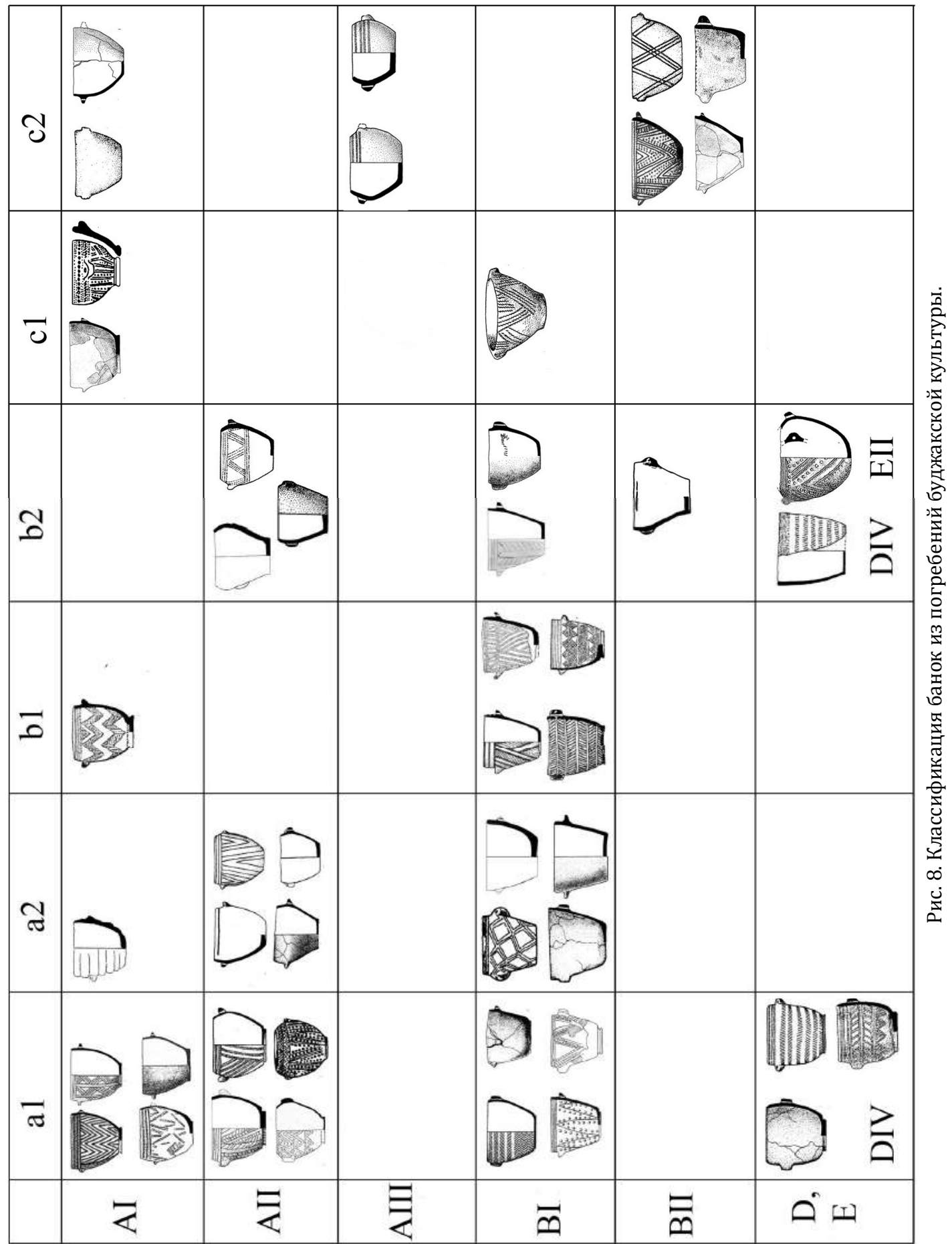


Aски (6 экз.). Этот тип сосудов также достаточно редкий и почти неизвестный к востоку от Южного Буга. Сосуды имеют петлевидную ручку, слегка скошенный венчик и почти всегда слегка асимметричное тулово (рис. 7.1-6). Два экземпляра не орнаментированы, на двух в месте перехода шейки в тулово имеются налепы в виде горошинок, еще на одном - ногтевые насечки в месте соединения тулова и венчика, который оказался обломанным в древности. Наиболее выразителен аск из разрушенного кургана у с. Матроска (рис. 7. 1).

Кувшины (9 экз.) не имеют стандартной формы, в них отсутствует слив, некоторые из них достаточно приземистых очертаний, так что название это достаточно условно; объединяет их наличие выделенного венчика и петлевидной ручки (рис. 7. 9-15). Один фрагментированный экземпляр украшен оттисками шнура. Два сосуда, помимо ручки, имеют (с противоположной от нее стороны) налеп, причем в захоронении Струмок $1 / 3$ налеп и стенка возле него, а также ручка и придонная часть украшены отпечатками шнура.

\section{Отдел 2: бесшейные сосуды.}

Банки - 84 экземпляра (18\%) - бесшейные сосуды усеченно-конической или полусферической формы, с парными ручками-налепами (рис. 8). Они являются характерной керамикой именно буджакской культуры, порой, к ним применяется термин «буджакские банки». Доминируют средние размеры (до 20 см высотой), имеются и небольшие, высотой до 10 см. Чаще всего сосуды покрыты ангобом, цвет варьирует в пределах оранжевых и розовых оттенков, есть и сероглиняные изделия. Банки, как правило, имеют симметрично расположенные ручки в верхней части тулова, выделяются их три варианта: 1) уплощенные, т. н. «язычковые» ручки с одним или двумя вертикально проколотыми отверстиями; 2) ручки в виде конических налепов, также имеющие одно или два проколотых отверстия; 3) вертикальные псевдотуннельные ручки, которые, в свою очередь, могут быть одинарными или парными, в последнем случае - сдвоенными или отстоящими друг от друга. Их изготавливали путем прокола отверстий в вертикальных налепах по сырой глине, что хорошо заметно при визуальном изучении керамики. Пожалуй, лишь на одном экземпляре (фрагмент стенки сосуда) прослеживается близость к настоящим туннельным ручкам, свернутым в трубочки - Новоселица 19/19.

Можно отметить два вида этой категории сосудов - на поддоне и без поддона, внутри каждого вида выделяются типы в зависимости от сочетания характерных признаков, внутри типов известны орнаментированные и неорнаментированные варианты. Преобладают сосуды без поддонов, орнаментированы оба вида банок.

Вид 1 - банки на поддоне (32 экз.) характеризуется средними и высокими пропорциями, по форме выделяются сферический тип Ala1, AIc1, AIIa1 и усеченоконический тип Bla1, BIb1. B первом случае край венчика часто загнут вовнутрь. Несколько экземпляров имеют цилиндрический облик - DIVa1. Этот тип банок орнаментирован чаще и разнообразнее, чем банки без поддона (орнамент присутствует на $2 / 3$ экземпляров). Композиции наносили в шнуровой технике и с помощью отпечатков полой трубочки. Помимо традиционного зигзага, имеется елочный орнамент и горизонтальные повторяющиеся фризы из треугольников. Зачастую орнамент, расположенный под ручками, отличен от основной композиции, порой, орнамент наносили на «язычковые» ручки, причем даже на сосуды с неорнаментированным туловом. 


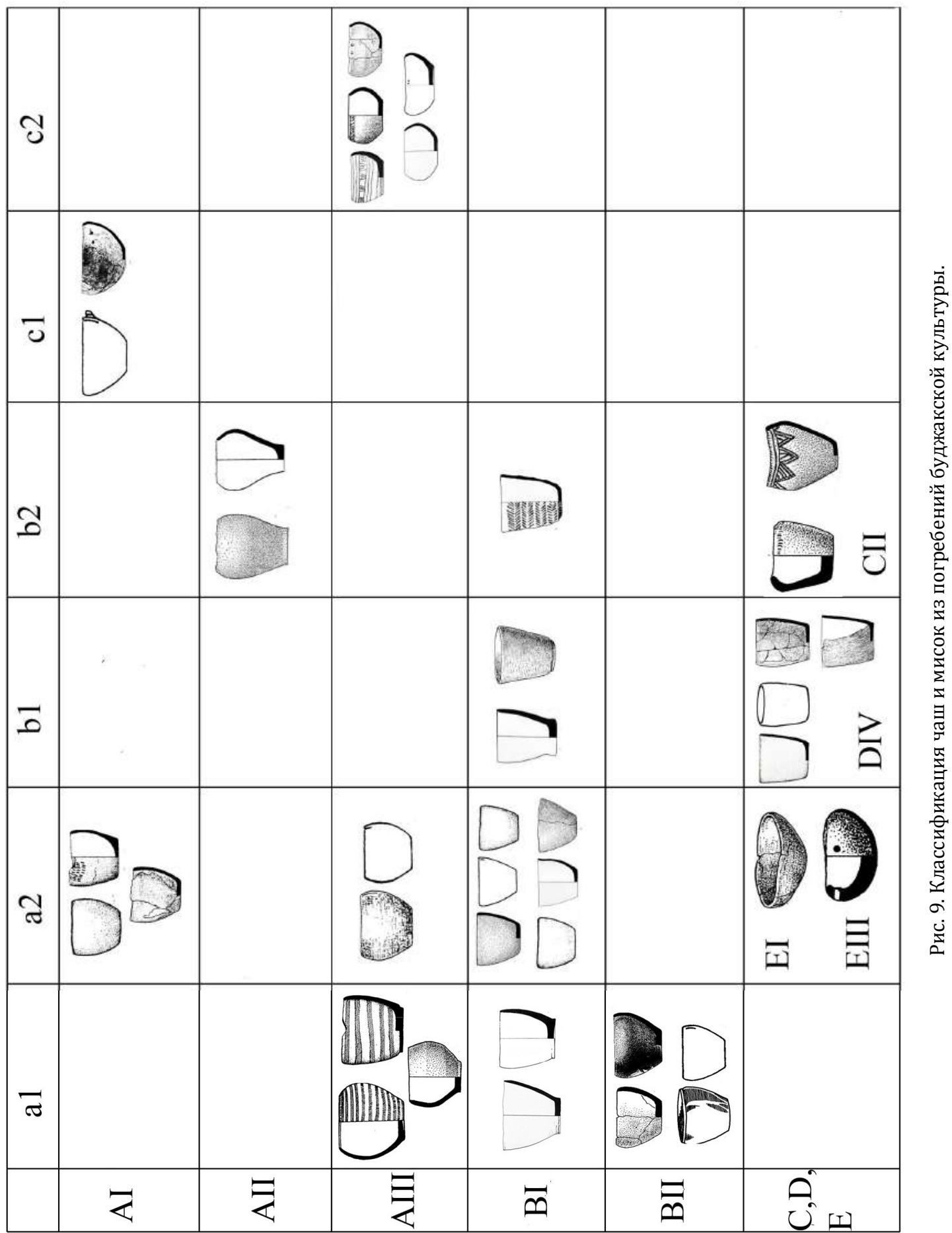


Вид 2 - банки без поддона (52 экз.). Банки отличаются по пропорциям, размерам и конфигурации. Преобладают банки усечено-конической формы средних размеров BIa2, BIb2, BIc2. Реже встречаются банки сферической формы - AIc1, AIIa2, AIIb2, AIIc2. Среди банок без поддонов известны сосуды со шнуровым орнаментом и без него, неорнаментированные экземпляры преобладают. Орнамент украшает полностью весь сосуд или только его верхнюю часть и достаточно разнообразен. Более простые варианты представляют собой параллельные горизонтальные отпечатки шнура, древовидную композицию. На иных сосудах орнаментация более сложная: многорядные зигзаги, ромбы, шевроны. Помимо шнура, для нанесения орнамента использовали полую трубочку. По-своему уникальны два сосуда - экземпляр с асимметричными насечками из Великозименово 1/2 и банка с двумя парами разных ушек из Мокра 1/3.

Чаши - 55 экземпляров (11,8\%) - представляют собой сосуды усеченоконической, реже полусферической формы, наибольший диаметр их не превышает высоту (рис. 9). Венчик у чаш может быть прямо срезан или слегка загнут вовнутрь, дно плоское, в единичных случаях округлое, высота варьирует в пределах 5-15 см. Выделяются чаши сферические AIa2, AIIIa1, AIIIa2, конические BIa1, BIa2 и цилиндрические DIVb1, последний тип самый малочисленный. Среди сферических выделяются две чаши, которые занимают промежуточное место между чашами и банками: форма, размеры и орнаментация сходны с баночными сосудами, но отсутствуют ручки, из-за чего они были включены в данную категорию посуды. Преобладают средние пропорции сосудов, высокие экземпляры единичны. Имеются редкие формы с расширением в верхней трети тулова. Изредка у чаш слегка выделено дна. Чаще всего поверхность хорошо заглажена.

Миски (13 экз.) - сосуды усечено-конической и полусферической форм, с диаметром устья или тулова, превышающим высоту изделия (рис. 9). Имеются экземпляры с «открытым» и «закрытым» устьем. Чаще миски не орнаментированы, на трех экземплярах имеется пара проколотых отверстий. На трех мисках присутствует орнамент: в двух случае нанесен оттисками шнура, в одном - отпечатками типа «птичье перо».

Кружки представлены двумя экземплярами, они не имеют выделенного венчика, круглые в сечении петельчатые ручки прикреплены к средней части тулова. Миниатюрными размерами отличается кружечка из погребения Новоградковка 2/9.

В заключение отметим, что все основные типы керамики, помимо средних форм, представлены сосудами небольших (5-10 см) размеров. В некоторых культурах такие сосуды относят к индивидуальным, но наличие порошка охры в некоторых из них позволяет предположить вотивный их характер - по крайней мере, для этих конкретных экземпляров.

Выводы. Классификационно-статистическая характеристика керамики, основанная на системном подходе, является наиболее приемлемой при рассмотрении посуды, изготовленной без помощи гончарного круга. Лепные сосуды буджакской культуры, даже происходящие с одного памятника, имеют определенные индивидуальные отличия. Использование системного подхода позволяет подойти к сравнительной характеристике керамики, опираясь на объективные критерии, основанные, прежде всего, на создании структурной схемы сосуда. К тому же именно в 
форме и орнаментации посуды чаще всего проявляются инокультурные влияния ${ }^{17}$. Этот фактор делает анализ керамических материалов особенно актуальным при рассмотрении проблем, связанных с реконструкцией культурно-исторических процессов.

\section{REFERENCES}

Alekseeva, I.L. (1992). Kurgany epokhi paleometalla v Severo-Zapadnom Prichernomore. [Paleometal mounds in the Northwest Black Sea region]. Kiev: Naukova dumka [in Russian].

Bokovenko, N.A. (1991). Etiud o skifskikh bronzovikh kotlakh Severnogo Prichernomoria [Study on Scythian Bronze Cauldrons of the Northern Black Sea Region]. In Klein, L.S. Arkheologicheskaia tipologiia. (pp. 256-263). Leningrad: AN SSSR [in Russian].

Bochkarev, V.S. (1991). Klassifikatsiia $v$ arkheologii. Terminologicheskii slovar-spravochnik [Classification in archaeology. Terminology dictionary]. Moskva: Nauka [in Russian].

Bratchenko, S.N. (1976). Nizhnee Podonie v epokhu srednei bronzy [Lower Don region in the Middle Bronze Age]. Kiev: Naukova dumka [in Russian].

Dergachev, V.A. (1986). Moldaviia i sosednie territorii $v$ epokhu bronzy [Moldova and neighboring territories in the Bronze Age]. Kishinev: Shtiintsa [in Russian].

Ivanova, S.V. (2013). Yamnaia (budzhakskaia) kultura Severo-Zapadnogo Prichernomoria [The Yamnaia (Budzhak) culture of the Northwest Black Sea Region]. In Bruiako, S., Samoilova, T. (Eds). Drevnie kultury Severo-Zapadnogo Prichernomoria, (pp. 211-254). Odessa: SMIL [in Russian].

Ivanova, S.V. (2013). Tipologiia i klassifikatsyia amfor iz pogrebenii budzhakskoi kultury SeveroZapadnogo Prichernomoria [Typology and classification of amphoras from burials of the Budzhak culture of the North-Western Black Sea Region]. In Nemchenko, I. et al. (Eds.). Drevnee Prichernomoryi, (Vol. X, pp. 256-266). Odessa: FLP «A.S. Fridman» [in Russian].

Ivanova, S.V. (2013). Kulturno-istoricheskie kontakty naseleniya Severo-Zapadnogo Prichernomorya v rannem bronzovom veke: Zapad-Vostok [Cultural and historical contacts of the population of the Northwest Black Sea Region in the Early Bronze Age: West - East]. Stratum plus, 2, 199-258 [in Russian].

Klein, L.S. (1979). Poniatie tipa v sovremennoi arkheologii [The concept of type in modern archeology]. In Klein, L. (Ed.). Tipy v culture, (pp. 50-74). Leningrad: LGU [in Russian].

Klein, L.S. (1991). Arkheologicheskaia tipologiia [Archeological typology]. Leningrad: AN SSSR [in Russian].

Manzura, I.V. (2001-2002). Problema formirovaniia kultur rannego bronzovogo veka na SeveroVostochnykh Balkanakh [The problem of the formation of cultures of the early Bronze Age in the Northeast Balkans]. Stratum plus, 2, 468-485 [in Russian].

Matiushin, G.N. (1995). Arkheologicheskii slovar [Archeological dictionary]. Moskva: Prosveschenie [in Russian].

Mochalov, O.D. (2008). Keramika pogrebalnykh pamiatnikov epokhi bronzy lesostepi Volgo-Uralskogo mezhdurechia [Ceramics of funeral monuments of the Bronze Age of the forest-steppe of the VolgaUral interfluve]. Samara: SGPU [in Russian].

Nikolova, A.V. \& Mamchich, T.I. (1997). Do metodyky klasifikatsii posudu yamnoi kultury [To the methodology of classification of the dishes of Yamna culture]. Arkheolohia, 3, 101-115 [in Ukrainian].

Patokova, E.F., Petrenko, V.G., Burdo, N.B. \& Polishchuk, L.U. (1989). Pamiatniki tripolskoi kultury $v$ Severo-Zapadnom Prichernomorie [Monuments of Tripolie culture in the North-Western Black Sea region]. Kiev: Naukova dumka [in Russian].

Petrenko, V.G., Ostroverkhov, A.S. \& Sapozhnikov, I.V. (2002). Novyi kurgan epokhi eneolita-bronzy v Nizhnem Podnestrove [New mound of the Eneolithic-Bronze Age in the Lower Dniester]. Starozhitnosti Stepovogo Prychornomoria ta Krymu, X, 39-63 [in Russian].

Pustovalov, S.Zh. (2001). Klassifikatsiia katakombnoi keramiki [Catacomb Ceramic Classification]. Epokha bronzy Dono-Donetskogo regiona. Materialy 5-go Ukrainsko-Rossiiskogo polevogo arkheologicheskogo seminara, (pp. 88-95). Kiev-Voronezh [in Russian].

Shaposhnikova, O.G., Fomenko, V.N. \& Dovzhenko, N.D. (1986). Yamnaia kulturno-istoricheskaia oblast (yuzhnobugskii variant) [The Yamnaia cultural and historical region (South Bug variant)]. Kiev: Naukova dumka[in Russian].

\footnotetext{
17 Иванова С.В. Культурно-исторические контакты населения Северо-Западного Причерноморья в раннем бронзовом веке: Запад-Восток // Stratum plus. 2013. № 2. С. 199-258.
} 
Sher, Ya.A. (1966). Tipologicheskii metod v arkheologii i statistika [Typological method in archeology and statistics]. VII Mezhdunarodnyi kongress doistorikov i protoistorikov. Doklady i soobshcheniia arkheologov SSSR. Moskva, 253-266 [in Russian].

Subbotin, L.V. (2000). Severo-Zapadnoe Prichernomore v epokhu rannei i srednei bronzy [SeveroZapadnoe Prichernomore v epokhu rannei i srednei bronzy]. Stratum plus, 2, 350-387 [in Russian].

Toshchev, G.N. (1987). Srednii period bronzovogo veka iugo-zapada SSSR [The average period of the Bronze Age of the south-west of the USSR]. Zaporozhie. INION AN SSSR (deponent) 19.06.1987. N 29903 [in Russian].

Yarovoi, E.V. (1985). Drevneishie skotovodcheskie plemena yugo-zapada SSSR (klassifikatsyia pogrebalnogo obriada) [The oldest cattle breeding tribes of the south-west of the USSR (classification of the funeral rite)]. Kishinev: Shtiintsa [in Russian].

\section{Svitlana Ivanova}

(Institute of Archaeology of National Academy of Sciences of Ukraine, Kyiv, Ukraine)

ORCID: https://orcid.org/0000-0002-3318-8244

\section{The systemic approach in a classification of ceramics of the Budzhak culture}

The Budzhak culture that is a component of the Yamnaya cultural-historical region. The pottery (467 intact and restored vessels) comprises over $40 \%$ of the total number of finds. The production technique used to make the vessels was a traditional one: handmade, with admixtures of grog, limestone or sand, with the surface treatment with a putty knife, tufts of vegetation, glazers. The colour varies from rose and yellow hues to dark-grey. The surface of some kind of vessels is covered with engobe.

The most common pottery forms on the north-western Black Sea Coast are pots $(34.5 \%)$, 'Budzhak pots' ('jars') (18\%), small amphorae and amphora-like vessels (12.2\%), bowls (12\%), large-size ('corded') amphorae (4.5\%), GAC vessels (2\%). In the Dniester-Prut interfluve, percentage shares of individual pottery forms are as follows: pots $-45 \%$, 'Budzhak pots' ('jars') and pot-like vessels - 9\%, small amphorae and amphora-like vessels $-4.5 \%$, and bowls $-5.5 \%$. Some types are so rare that only single specimens occur, while others are quite common, for instance, bowls.

The article describes the methodology for the classification of ceramics of Budzhak culture from the North-Western Black Sea region. Our work was based on a formal and typological method, which is traditional in archaeology. But elements of system analysis were also used. The systematic method allowed objectively developing classification schemes for various types of dishes. Each type of ceramic has a certain structure, which manifests itself in a system of features - constituent elements of a vessel.

The shape of the vessel and its structure are interconnected. Consideration of the structure, i.e. a combination of various morphological features characterizing the vessel defines a systematic approach to construction of various classifications of Eneolithic and Bronze Age ceramics of different territories. The following hierarchical systematisation scheme of ceramics is used in the work: order - category - type - variance.

The classification and statistical characteristics of ceramics, based on the systematic approach, are most acceptable when considering dishes made without a potter's wheel. The molded vessels of the Budzhak culture, even originating from a same site, have certain individual differences. Application of the systemic method allows to refine the comparative characteristics of ceramics, relying on objective criteria. They are based, first of all, on creating a structural diagram of a vessel. The outsider cultures are best manifested in a shape and ornamentation of pottery. This factor makes the analysis of ceramic materials especially relevant when considering problems associated with the reconstruction of cultural and historical processes.

Keywords: ceramics, Budzhak's culture, North-Western Black Sea coast 